\title{
Inactivation of Lysosomal Proteases by Oxidized Low Density Lipoprotein Is Partially Responsible for Its Poor Degradation by Mouse Peritoneal Macrophages
}

George Hoppe, June O'Neil, and Henry F. Hoff

Department of Cell Biology, Research Institute, The Cleveland Clinic Foundation, Cleveland, Ohio 44195

\begin{abstract}
Deficient processing of apo B in oxidized LDL (ox-LDL) by macrophage lysosomal proteases has been documented and attributed to modifications in apo $B$. We have investigated whether direct inactivation of lysosomal proteases by oxLDL could also be responsible for this deficient degradation. When mouse peritoneal macrophages (MPM) were preincubated for $21 \mathrm{~h}$ at $37^{\circ} \mathrm{C}$ with ox-LDL, LDL, or vortex-aggregated LDL, only ox-LDL inhibited the subsequent degradation of ${ }^{125}$ I-labeled forms of the above lipoproteins. Uptake of labeled lipoproteins was not appreciably affected by preincubation with ox-LDL, suggesting that the inhibition was at the level of lysosomal degradation. Thiol protease activity of cell extracts at pH 4.0, was reduced in MPM preincubated with ox-LDL relative to cells preincubated with LDL or medium alone. Extracts from untreated MPM, or mixtures of cathepsin $B$ and $D$, showed a reduced ability to degrade ${ }^{125}$ I-LDL at pH 4.5 and reduced cathepsin $B$ activity, after incubation with ox-LDL relative to incubation with LDL. Thus, the reduced degradation of lipoproteins in MPM pretreated with ox-LDL could be due to direct inactivation of the lysosomal protease, cathepsin B. (J. Clin. Invest. 1994. 94:1506-1512.) Key words: oxidized LDL - mouse peritoneal macrophages • lysosomal enzymes • cathepsin B • cathepsin D
\end{abstract}

\section{Introduction}

Incubation of primary cultures of macrophages with oxidized LDL (ox-LDL) ${ }^{1}$ was shown to induce lipid loading $(1,2)$. After long-term incubation with ox-LDL, most of this lipid is contained within lysosomes, primarily in the form of lipid-protein complex called ceroid (3). By contrast, macrophage degradation of acetylated LDL (acetyl-LDL) results in cellular accu-

Address correspondence to Henry F. Hoff, Ph.D., Department of Cell Biology, NC-10, Research Institute, The Cleveland Clinic Foundation, 9500 Euclid Avenue, Cleveland, OH 44195.

Received for publication 15 February 1994 and in revised form 24 May 1994.

1. Abbreviations used in this paper: acetyl-LDL, acetylated LDL; BHT, butylated hydroxytoluene; CLN, N $\alpha$-CBZ-L-lysine $p$-nitrophenyl ester; HNE, 4-hydroxynonenal; LP, lipoprotein; MPM, mouse peritoneal macrophage; ox-LDL, oxidized LDL; vx-LDL, vortexed LDL.

J. Clin. Invest.

(C) The American Society for Clinical Investigation, Inc.

0021-9738/94/10/1506/07 $\$ 2.00$

Volume 94, October 1994, 1506-1512 mulation of cholesteryl oleate droplets in the cytoplasm (4). Recently, several groups have shown that following internalization of ox-LDL by macrophages, apo B, the protein portion of the LDL, was poorly degraded within cellular lysosomes (58 ). Additionally, it was shown that the poor proteolysis of oxLDL also occurred in cell-free systems such as extracts of mouse peritoneal macrophages (MPM) $(7,8)$, or with mixtures of cathepsin B and D $(6,9)$. Reduction in proteolysis was shown to correlate with the degree of oxidation (8). It was shown that proteolysis by lysosomal enzymes decreased with increasing degree of crosslinking of apo B in LDL that was induced using 4-hydroxynonenal (HNE) (8). These authors reasoned that the deficient degradation of apo $B$ in ox-LDL was due to a reduced susceptibility of the modified portions of apo $B$ in ox-LDL to proteolysis.

An alternative explanation for this poor processing of oxLDL protein is that the ox-LDL is directly able to inactivate lysosomal proteases. Several reports have appeared showing that reactive aldehydes, such as HNE, formed by the decomposition of hydroperoxides (10), can form covalent linkages with enzymes, thereby inactivating them $(10-12)$. This is particularly true of enzymes with active sites containing thiol groups, because thiol-ether adducts can be formed by the Michael addition mechanism $(11,12)$.

In this report, we attempted to assess whether lysosomal protease inactivation could be, in part, responsible for this deficient processing. Three approaches have been used. First, we asked whether preincubation of MPM with ox-LDL affected the subsequent degradation of other lipoproteins (LPs). Second, we ascertained whether extracts of cells that had been preincubated with ox-LDL demonstrated a reduction in proteolytic activity. And third, we determined whether ox-LDL could directly affect the proteolytic activity of cell extracts or purified proteases.

\section{Methods}

Materials. Cathepsin B (EC 3.4.22.1) (C 6286), cathepsin D (EC 3.4.23.5) (C 3138), N $\alpha$-CBZ-L-lysine $p$-nitrophenyl ester (CLN) (C 3637), fatty acid-free BSA, butylated hydroxytoluene (BHT), TCA, DTT, and $\mathrm{Na}_{2}$ EDTA were purchased from Sigma Chemical Co. (St. Louis, MO). Carrier-free Na ${ }^{125}$ I was from ICN Biomedicals, Inc. (Irvine, CA), RPMI 1640 was from Whittaker Bioproducts (Walkersville, MD), FCS was from Gibco Laboratories (Grand Island, NY), and the bicinchoninic acid assay reagents were from Pierce Chemical Co. (Rockford, IL). Tissue culture plates were obtained from Costar Corp. (Cambridge, MA), spectra/Por 2 dialysis tubing from Spectrum Medical Industries, Inc. (Los Angeles, CA), and C57BL/6 mice (16-20 wk of age) from Trudeau Institute (Saranac Lake, NY).

Lipoproteins. LDL was isolated from fresh plasma obtained from the Cleveland Clinic Blood Bank by sequential ultracentrifugation as a $1.019<d<1.063 \mathrm{~g} / \mathrm{ml}$ fraction using the procedure of Hatch and 
Lees (13). The LDL was dialyzed against $0.15 \mathrm{M} \mathrm{NaCl}$ containing 0.5 $\mathrm{mM} \mathrm{Na} \mathrm{E}_{2} \mathrm{EDTA}$, pH 8.5, filter-sterilized and stored at $4^{\circ} \mathrm{C}$. LDL was labeled with $\mathrm{Na}^{125}$ I using the iodine monochloride procedure of McFarlane (14) as modified by Bilheimer et al. (15); the specific activity of labeled preparations was between 100 and $200 \mathrm{cpm} / \mathrm{ng}$ protein. LP concentrations are routinely expressed as $\mu \mathrm{g}$ of protein $/ \mathrm{ml}$. Acetylation of LDL was performed by repeated additions of acetic anhydride (16) and then extensively dialyzed against $0.15 \mathrm{M} \mathrm{NaCl}$ containing $0.3 \mathrm{mM}$ $\mathrm{Na}_{2}$ EDTA, pH 7.4. Oxidation of ${ }^{125} \mathrm{I}$-labeled and unlabeled $\mathrm{LDL}$ was performed in the presence of $10 \mu \mathrm{M} \mathrm{CuSO}_{4}$ in $0.15 \mathrm{M} \mathrm{NaCl}$ at a protein concentration of $500 \mu \mathrm{g} / \mathrm{ml}$ for $24 \mathrm{~h}$ at $20^{\circ} \mathrm{C}(2,9)$. The concentration of EDTA in LDL preparations was reduced prior to oxidation by overnight dialysis against $0.15 \mathrm{M} \mathrm{NaCl}$. Oxidation was terminated by dialyzing samples into $0.15 \mathrm{M} \mathrm{NaCl}, 0.3 \mathrm{mM} \mathrm{Na}{ }_{2} \mathrm{EDTA}$, and $20 \mathrm{mM}$ Na phosphate, $\mathrm{pH} 7.4$, for $2 \mathrm{~h}$. Soluble and insoluble forms of LDL, oxidized for $24 \mathrm{~h}$ as previously described (9), were separated by centrifugation at $10,000 \mathrm{~g}$ for $10 \mathrm{~min}$. The supernatant fraction, designated soluble oxLDL, contain small aggregates of about four to six particles (9). The precipitated fraction was designated insoluble ox-LDL and typically represented about $80 \%$ of the total ox-LDL. The degree of oxidation, measured by the conjugated dienes content or fluorescence ( 360 excitation/430 emmission), was similar for individual soluble and insoluble ox-LDL samples used in this study. Aggregated LDL was produced by vortexing solutions of $\mathrm{LDL}(500 \mu \mathrm{g} / \mathrm{ml}$ in $0.15 \mathrm{M} \mathrm{NaCl}$ containing 0.3 $\mathrm{mM} \mathrm{Na}{ }_{2}$ EDTA). Butylated hydroxytoluene (BHT) dissolved in ethanol was added at a final concentration of $40 \mu \mathrm{M}$ to prevent oxidation. Vortexing was performed at $20^{\circ} \mathrm{C}$ for 1 min using a benchtop Vortex (Genie, Scientific Products, McGaw Park, IL) at high-speed setting (17). The insoluble portion of LDL, prepared as described above, was designated vortexed (vx-) LDL.

Lipoprotein uptake and degradation by cultured cells. MPMs were harvested 2-3 d after thioglycollate stimulation of female C57BL/6 mice by peritoneal lavage with ice-cold PBS. Primary cultures were prepared at a density of $10^{6}$ cells $/ 16 \mathrm{~mm}$ diameter well in RPMI 1640 containing $10 \%$ FCS and used $48 \mathrm{~h}$ after plating (9). Cells were washed with serum-free RPMI and the indicated concentration of unlabeled native or modified LDL added in $250 \mu \mathrm{l}$ of the medium containing FCS as described above. After overnight incubation, cells were washed and incubated with labeled native or modified LDL for another $5 \mathrm{~h}$. The media were then removed and assayed for TCA-soluble, noniodine degradation products according to the procedure described previously ( 5 , 9). Cells were washed three times with PBS, dissolved in $0.25 \mathrm{~N} \mathrm{NaOH}$, and assayed for cell-associated label and protein content. Total uptake was calculated from the sum of degradation and cell-associated label. All determinations are reported as mean \pm SD of triplicate determinations.

Proteolytic activity of macrophage extracts. MPM were isolated from thioglycollate-elicited mice as described above. Cells were grown in 100 -mm Petri dishes $\left(20 \times 10^{6} /\right.$ dish $)$ and incubated for $18 \mathrm{~h}$ in medium alone or medium containing native or modified LDL at the indicated concentrations. At the end of the incubation, macrophage monolayers were washed twice with PBS followed by one wash with $250 \mathrm{mM}$ sucrose, $1 \mathrm{mM} \mathrm{Na}{ }_{2}$ EDTA, and $0.1 \%$ ethanol, $\mathrm{pH} \mathrm{6.8}$. Scraped cells were pelleted by centrifugation at $2,000 \mathrm{~g}$ for $10 \mathrm{~min}$ and resuspended in $1 \mathrm{ml}$ of the sucrose solution described above. Then, the cells were ruptured by passing 10 times through a 30-gauge needle, followed by 10 cycles of freezing and thawing, and finally by two 15 -s bursts of sonication (8). The homogenates were spun again at $5,000 \mathrm{~g}$ to remove particulate matter and supernatant fractions, defined in this study as cell extracts, were collected, aliquoted, frozen at $-70^{\circ} \mathrm{C}$, and subsequently used in experiments over a period of 2 mos. $5 \mu \mathrm{g}$ of cell extract protein was mixed with the indicated concentrations of ${ }^{125} \mathrm{I}-\mathrm{LDL}$ in a final volume of $100 \mu \mathrm{l}$ of $100 \mathrm{mM}$ sodium acetate, $1 \mathrm{mM} \mathrm{Na} \mathrm{F}_{2}$ EDA, and 1 $\mathrm{mM}$ DTT, $\mathrm{pH} 4.0$, and incubated for $1.5 \mathrm{~h}$ at $37^{\circ} \mathrm{C}$. The degradation of the radioactive substrate was measured as TCA-soluble, noniodine radioactivity. Cathepsin B activity of macrophage extracts was assayed as follows: $0.5 \mu \mathrm{g}$ of extract was mixed with $500 \mu \mathrm{l}$ of acetate buffer, $\mathrm{pH} 4.0$, containing CLN at a final concentration of $2 \times 10^{-4} \mathrm{M}$ and absorbance at $326 \mathrm{~nm}$ monitored over a 30 -min time interval (18). To determine the proteolytic activity of enzymes that have been stimulated by the addition of DTT, we conducted all experiments in the presence and absence of DTT. DTT-dependent proteolysis was determined as total degradation (DTT present) minus DTT-independent degradation (DTT omitted).

Cathepsin degradation. Digestion of LPs by cathepsins B and D was performed as described by Lougheed et al. (6) with some modifications. Briefly, the enzymes were activated by incubating $1 \mathrm{vol}$ of cathepsin B $(0.25 \mathrm{U} / \mathrm{ml})$ and $1 \mathrm{vol}$ of cathepsin $\mathrm{D}(0.25 \mathrm{U} / \mathrm{ml})$ in $2 \mathrm{vol} 0.2 \mathrm{M}$ acetate buffer, $\mathrm{pH} 4.5$, containing $2 \mathrm{mM}$ DTT and $2 \mathrm{mM}$ EDTA for 15 $\min$ at $37^{\circ} \mathrm{C} .200 \mu \mathrm{l}$ of the activated enzymes were added to the indicated concentrations of various forms of ${ }^{125} \mathrm{I}$-labeled LDL or ${ }^{125} \mathrm{I}$-labeled hemoglobin as an indicator of cathepsin D activity (19), and the final assay volume was brought to $500 \mu \mathrm{l}$ with $0.1 \mathrm{M}$ acetate buffer, $\mathrm{pH}$ 4.5 , containing $1 \mathrm{mM}$ DTT and $1 \mathrm{mM}$ EDTA. The degradation of the radiolabeled substrate (radioactivity that is soluble in $10 \%$ TCA) was measured in aliquots taken at various periods over a 24-h time interval. CLN hydrolysis by the enzyme mixture was assayed as follows: after preincubation of cathepsins B and D in the presence of various LPs for the indicated time periods, $25 \mu \mathrm{l}$ was added to $450 \mu \mathrm{l}$ of $0.2 \mathrm{M}$ acetate buffer, pH 4.5, containing $2 \mathrm{mM}$ DTT and $2 \mathrm{mM}$ EDTA. Reaction was initiated by the addition of CLN at a final concentration of $2 \times 10^{-4}$ M. Hydrolysis of CLN is expressed as changes in absorbance at 326 $\mathrm{nm}$ wavelength per time interval.

Analytic procedures. The protein content of LPs cells, and cell extracts was measured in triplicate by the bicinchoninic acid assay using BSA as a standard (20). Samples were diluted in $1 \%$ SDS to minimize turbidity. Samples were incubated for $60 \mathrm{~min}$ at $60^{\circ} \mathrm{C}$, and absorbance was measured at $595 \mathrm{~nm}$.

\section{Results}

Effect of preincubation of MPM with ox-LDL on the subsequent degradation of ${ }^{125}$ I-labeled lipoproteins. To determine whether uptake of ox-LDL by MPM affected the degradation of subsequently internalized LPs, we first incubated MPM under various conditions for $21 \mathrm{~h}$, removed the medium, and then incubated the cells with medium containing different ${ }^{125} \mathrm{I}-\mathrm{LP}$ for $5 \mathrm{~h}$ to determine the rates of cellular LP degradation. Since extensively oxidized LDL consists of soluble and insoluble portions (9), in initial experiments we studied the effect of these two forms of ox-LDL separately.

We first compared the effect of preincubation of MPM with insoluble ox-LDL, LDL, or medium alone on the subsequent degradation of ${ }^{125}$ I-insoluble ox-LDL. Insoluble ox-LDL greatly inhibited the subsequent degradation of ${ }^{125} \mathrm{I}$-insoluble ox-LDL (Fig. $1 a$ ), whereas preincubation of cells with LDL failed to inhibit this degradation relative to medium alone (not shown). Since incubation with insoluble ox-LDL led to substantial intracellular accumulation of unprocessed LP (9), we compared the effect of preincubation with insoluble ox-LDL on subsequent $L P$ degradation with that of preincubation with LDL made insoluble by vortex aggregation (vx-LDL) as a control for the accumulation of undegraded but nonoxidized LP. We found that cells preincubated with vx-LDL did not inhibit the degradation of either ${ }^{125} \mathrm{I}$-insoluble ox-LDL or ${ }^{125} \mathrm{I}-\mathrm{vx}$-LDL (Fig. 1a). Since the preincubation of cells with unlabeled vxLDL had no effect on the degradation of subsequently added ${ }^{125} \mathrm{I}-\mathrm{vx}-\mathrm{LDL}$, it is unlikely that a transient overloading of the lysosomal degradation system was responsible for the inhibition in degradation of ox-LDL by preincubating cells with ox-LDL. To determine whether induction of phagocytosis was responsi- 

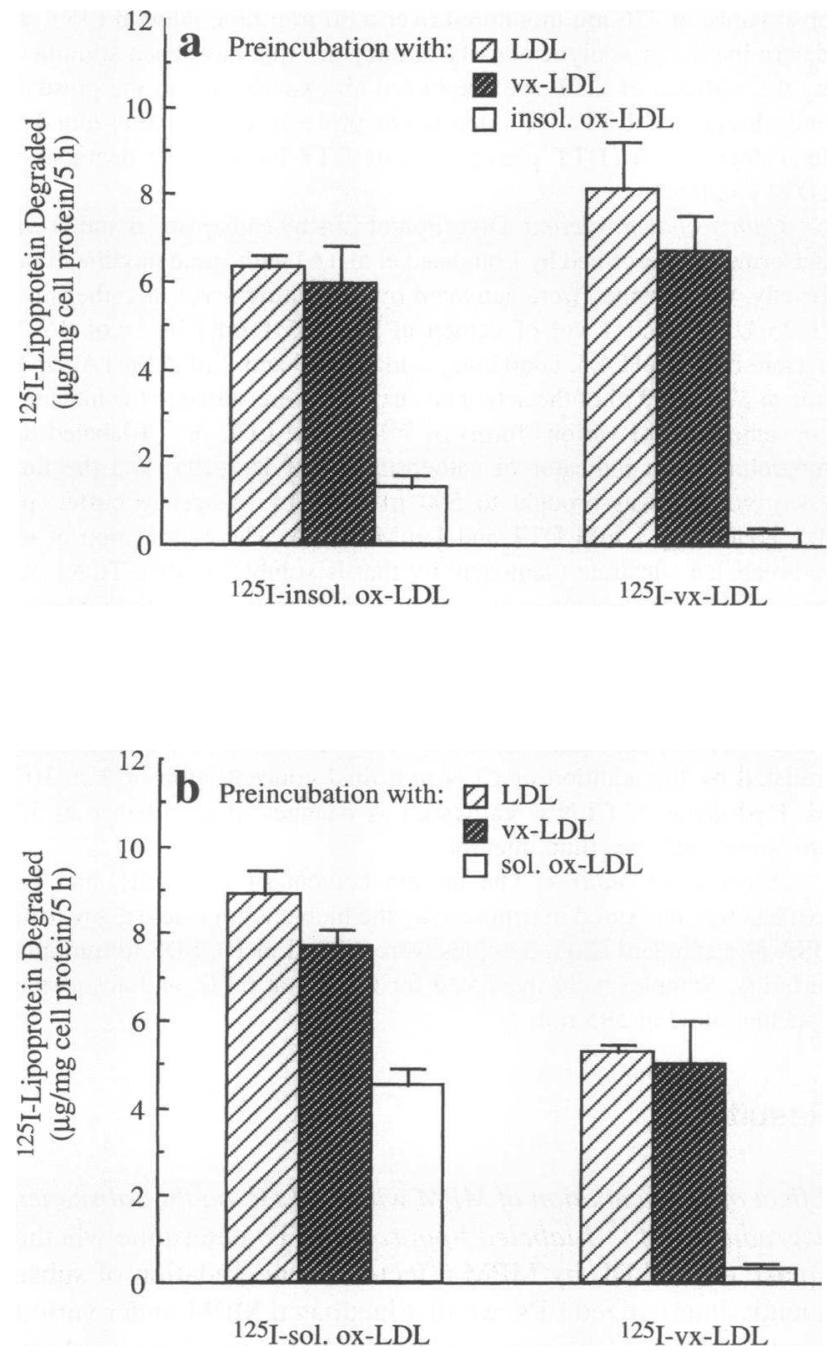

Figure 1. Preincubation of MPM with ox-LDL leads to inhibition of subsequent LP degradation. (a) MPM were preincubated with $50 \mu \mathrm{g}$ / $\mathrm{ml}$ of LDL, vx-LDL, or insoluble (insol.) ox-LDL for $21 \mathrm{~h}$. Then, cells were washed and incubated for $5 \mathrm{~h}$ with fresh medium containing 20 $\mu \mathrm{g} / \mathrm{ml}$ of ${ }^{125} \mathrm{I}$-insol. ox-LDL or ${ }^{125} \mathrm{I}-\mathrm{vx}-\mathrm{LDL}$. (b) MPM were preincubated with $100 \mu \mathrm{g} / \mathrm{ml}$ of LDL, vx-LDL, or soluble (sol.) ox-LDL for $21 \mathrm{~h}$. Then, cells were washed and incubated for $5 \mathrm{~h}$ with fresh medium containing $20 \mu \mathrm{g} / \mathrm{ml}$ of ${ }^{125} \mathrm{I}$-sol. ox-LDL or ${ }^{125} \mathrm{I}-\mathrm{vx}$-LDL. The amount of ${ }^{125}$ I-ligand degraded (iodine-free, TCA-soluble, radioactivity in medium) was determined as described in Methods.

ble for this inhibition, we preincubated cells with opsonized latex beads. Again, no reduction in the degradation of either ${ }^{125} \mathrm{I}$-insoluble ox-LDL or ${ }^{125} \mathrm{I}-\mathrm{vx}-\mathrm{LDL}$ was observed (not shown), indicating that phagocytosis, per se, was not responsible for this reduced degradation.

We also wished to assess whether soluble ox-LDL was also able to inhibit subsequent degradation of itself. As in the case with insoluble ox-LDL, preincubation of MPM with soluble oxLDL, in contrast to vx-LDL, inhibited the subsequent degradation of either labeled soluble ox-LDL or vx-LDL (Fig. $1 b$ ). Degradation of ${ }^{125} \mathrm{I}-\mathrm{LDL}$ was inhibited by preincubating MPM with either soluble or insoluble ox-LDL $(0.07 \pm 0.02$ and $0.045 \pm 0.003 \mu \mathrm{g} / \mathrm{mg}$ cell protein). Preincubation with vx-LDL

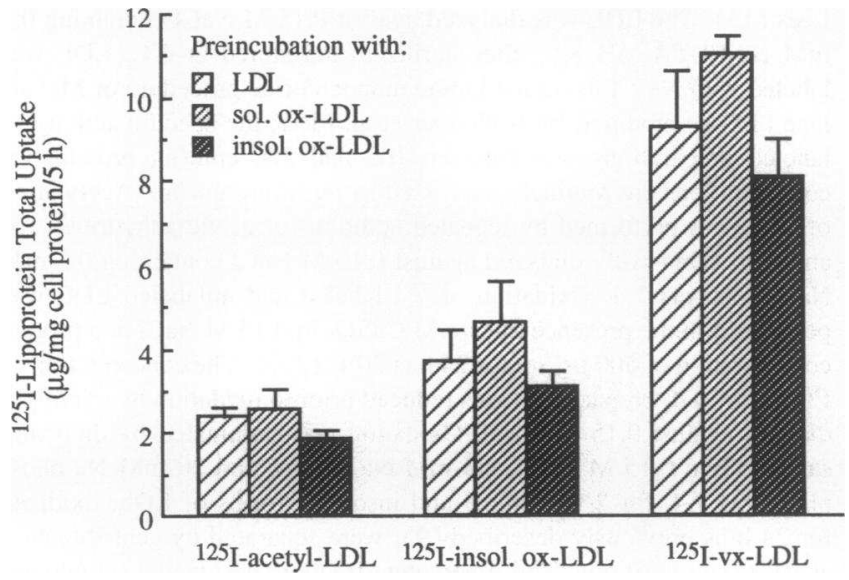

Figure 2. Total uptake by MPM of modified forms of LDL is not affected by preincubation of cells with ox-LDL. MPM were preincubated with $50 \mu \mathrm{g} / \mathrm{ml}$ of LDL, sol. ox-LDL, or insol. ox-LDL for $21 \mathrm{~h}$. Cells were then washed and incubated for $5 \mathrm{~h}$ with fresh medium containing $2.5 \mu \mathrm{g} / \mathrm{ml}$ of ${ }^{125} \mathrm{I}$-acetyl-LDL, ${ }^{125} \mathrm{I}$-insol. ox-LDL, or ${ }^{125} \mathrm{I}-\mathrm{vx}$ LDL. Total uptake was determined from the sum of degradation and accumulation of undegraded LP measured as described in Methods.

did not differ significantly from the preincubation with LDL $(0.1 \pm 0.02 \mu \mathrm{g} / \mathrm{mg}$ cell protein $)$. Thus, ox-LDL is able to inhibit the degradation of not only ox-LDL but other LPs as well.

To assess whether the described reduction in degradation was the result of decreased lysosomal degradation or uptake, possibly the result of inhibition of phagocytosis of insoluble LP, we determined the effect of preincubation of MPM with ox-LDL on LP uptake. After preincubating MPM with soluble or insoluble ox-LDL as well as with LDL, no major reduction in the subsequent uptake of any of the labeled LP employed was found (Fig. 2), suggesting that this inhibition in LP degradation was probably at the level of lysosomal degradation and not on the uptake mechanism. Treatment of MPM with ox-LDL for $21 \mathrm{~h}$ did not lead to any loss of cell protein or any significant changes in MPM morphology, suggesting a lack of any general toxicity of ox-LDL on MPM under the conditions employed.

To determine whether insoluble ox-LDL and soluble oxLDL were equally effective in inhibiting the degradation in MPM of subsequently added LP, we added different concentrations of each to cells and assessed their relative effects on the degradation of ${ }^{125} \mathrm{I}$-insoluble ox LDL. As seen in Fig. $3 a, 25$ $\mu \mathrm{g} / \mathrm{ml}$ of insoluble ox-LDL was as effective as $100 \mu \mathrm{g} / \mathrm{ml}$ of soluble ox-LDL in inhibiting the degradation of ${ }^{125} \mathrm{I}$-insoluble ox-LDL relative to preincubation with medium alone. We also determined in a parallel experiment the uptake of ${ }^{125} \mathrm{I}$-soluble and insoluble ox-LDL after incubation of MPM for $21 \mathrm{~h}$. As seen in Fig. $3 b$, the uptake of $25 \mu \mathrm{g} / \mathrm{ml}$ of insoluble ox-LDL was about the same as that of $100 \mu \mathrm{g} / \mathrm{ml}$ of soluble ox-LDL. Thus, when normalized for equivalent degrees of uptake, it appears that soluble and insoluble ox-LDL had about equal abilities to inhibit the degradation of other LP, consistent with the similar degree of oxidation. Based on these results, we have described the effects of ox-LDL generically in the studies described below.

Since both ox-LDL as well as acetyl-LDL are recognized by the scavenger receptor on MPM (5), one would anticipate 

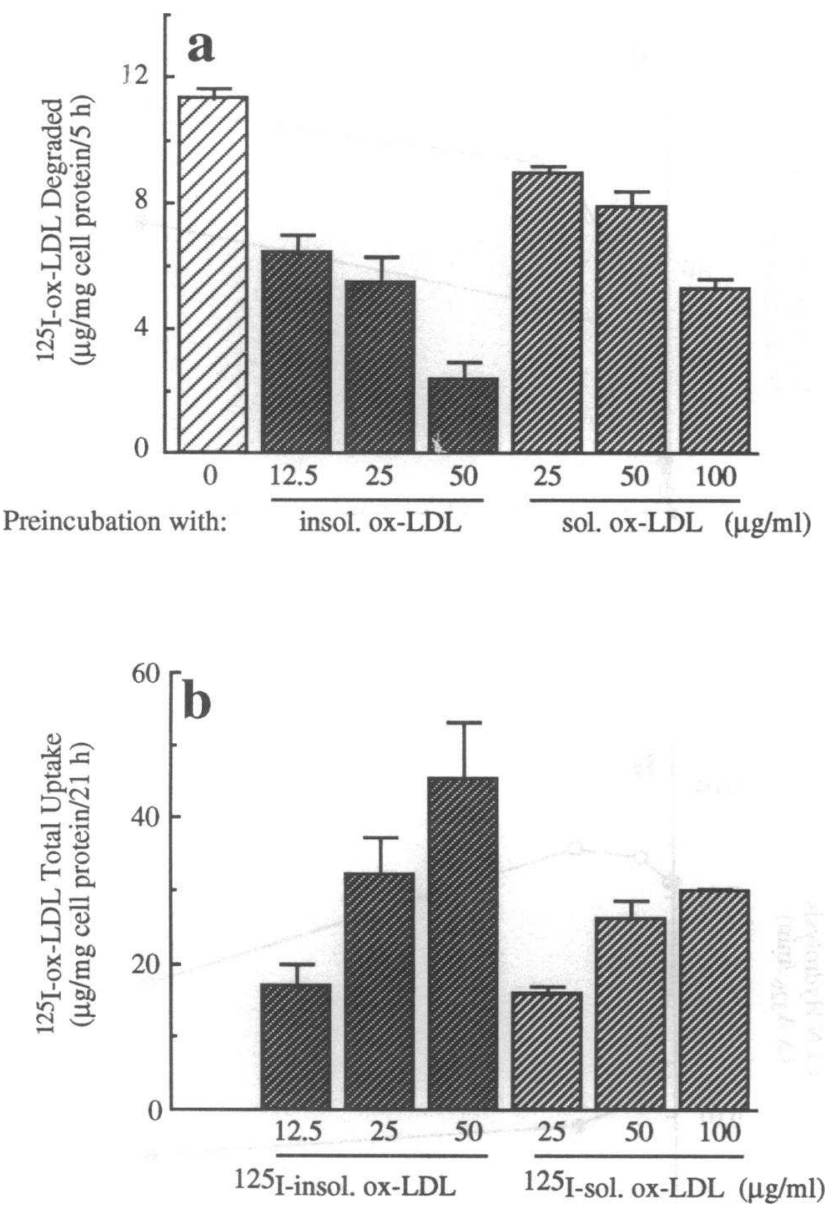

Figure 3. Preincubation of MPM with sol. and insol. ox-LDL demonstrate equal inhibition of the subsequent degradation of ${ }^{125}$ I-insol. oxLDL when normalized for equal uptake. (a) MPM were preincubated with the indicated concentrations of sol. ox-LDL, insol. ox-LDL, or medium alone for $21 \mathrm{~h}$. Cells were then washed and incubated for $5 \mathrm{~h}$ with fresh medium containing $20 \mu \mathrm{g} / \mathrm{ml}$ of ${ }^{125}$ I-inso!. ox-LDL. Degradation was determined as the amount of TCA-soluble label in the medium measured as described in Methods. (b) MPM were incubated with the indicated concentrations of ${ }^{125} \mathrm{I}$-sol. ox-LDL or ${ }^{125} \mathrm{I}$-insol. ox-LDL for $21 \mathrm{~h}$. Total uptake of ox-LDL was determined from the sum of degradation and accumulation of undegraded ox-LDL as indicated in Methods.

that the two ligands would follow the same intracellular route. However, pretreatment of cells with ox-LDL gave no reduction in the degradation of ${ }^{125} \mathrm{I}$-acetyl LDL $(2.29 \pm 0.22 \mu \mathrm{g} / \mathrm{mg}$ cell protein for preincubation with no LP and $2.30 \pm 0.46$ for preincubation with ox-LDL). By contrast, degradation of ${ }^{125} \mathrm{I}-\mathrm{vx}-\mathrm{LDL}$ was greatly reduced by pretreatment of cells with ox-LDL (3.54 $\pm 0.17 \mu \mathrm{g} / \mathrm{mg}$ cell protein for preincubation with no LP and $0.99 \pm 0.06$ for preincubation with ox-LDL).

Effect of ox-LDL on lysosomal protease activity in MPM extracts. We asked whether the preincubation of MPM with oxLDL affected the proteolytic activity in extracts of these cells. MPM were incubated for $21 \mathrm{~h}$ in the presence of various modified LP, (i.e., vx-LDL, acetyl-LDL, or ox-LDL). Extracts of these cells were subsequently prepared, and the proteolytic activity of the extracts were assessed by their ability to degrade ${ }^{125}$ I-labeled LDL. Only extracts from macrophages that were

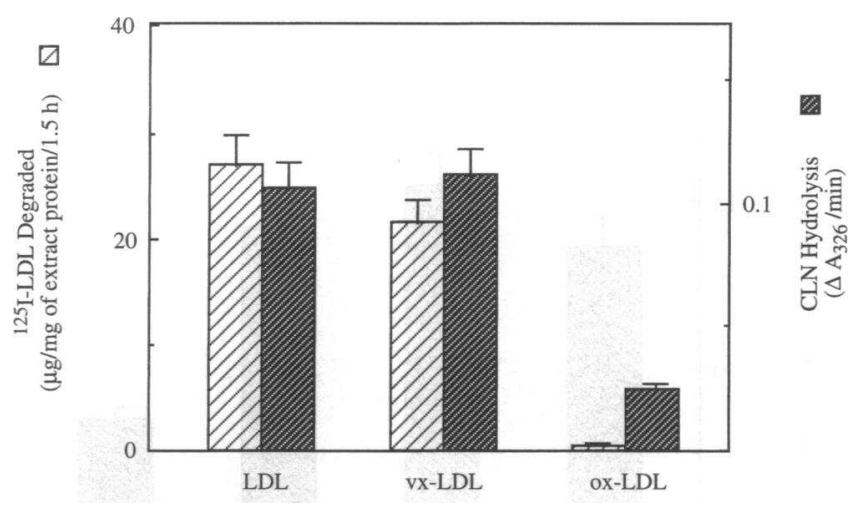

Figure 4. Pretreatment of MPM with ox-LDL results in reduced lysosomal thiol protease activity. MPM were preincubated with medium containing $50 \mu \mathrm{g} / \mathrm{ml}$ of native LDL, vx-LDL, or ox-LDL for $21 \mathrm{~h}$. Cells were washed and cell extracts were prepared by freezing-thawing and sonication. $5 \mu \mathrm{g}$ of protein from each extract were incubated with 150 $\mu \mathrm{g}$ of ${ }^{125} \mathrm{I}-\mathrm{LDL}$ in a final volume of $100 \mu \mathrm{l}$ of acetate buffer, $\mathrm{pH} 4.0$, for $1.5 \mathrm{~h}$ with and without DTT. $0.1 \mu \mathrm{g}$ of each extract was mixed with $2 \times 10^{-4} \mathrm{M} \mathrm{CLN}$ in a final volume of $500 \mu \mathrm{l}$ of acetate buffer, $\mathrm{pH} 4.0$ with and without DTT. TCA-soluble label (left ordinate) and CLN hydrolysis (right ordinate) were measured as described in Methods. Hydrolysis of CLN was expressed as changes in absorbance at $326 \mathrm{~nm} /$ $\min$.

preincubated with ox-LDL showed a major decrease in lysosomal thiol protease activity; i.e., degradation of LDL at pH 4.0 (Fig. 4) was assessed as DTT-dependent proteolysis. Similar levels of inhibition in thiol protease activity were found for the cells pretreated with soluble and insoluble ox-LDL when normalized for equivalent uptakes using values in Fig. 3.

To assess the activity of thiol proteases directly, CLN was used (18) as a specific substrate for cathepsin B, a thiol protease. Cathepsin B, along with cathepsin D, an aspartic protease, was shown to be a principal enzyme responsible for lysosomal digestion of LDL (6). MPM were first preincubated with vx-LDL, acetyl-LDL, or ox-LDL for $21 \mathrm{~h}$; then, extracts of these cells were prepared, and their individual cathepsin B activities were measured. We found that cathepsin B activity mimicked ${ }^{125} \mathrm{I}$ LDL degradation by extracts of cells preincubated with ox-LDL (Fig. 4).

Effect of ox-LDL on protease activity in extracts of untreated MPM and mixtures of cathepsin $B$ and $D$. To explore whether or not the documented reduction of proteolytic activity in MPM by ox-LDL was the result of direct interaction of ox-LDL with the enzyme, we incubated extracts from control macrophages with various forms of modified LDL. We found that ox-LDL, but not acetyl-LDL or vx-LDL, caused a significant decrease in DTT-sensitive proteolysis of ${ }^{125} \mathrm{I}$-LDL (Fig. 5 ). Both soluble and insoluble ox-LDL reduced thiol protease activity to the same degree (not shown).

To more specifically investigate whether ox-LDL can inactivate cathepsins $\mathrm{B}$ and $\mathrm{D}$, we compared the relative abilities of different forms of modified and unmodified LDL to inhibit these enzyme activities in a 1:1 mixture of cathepsin B and D using the CLN assay for cathepsin B activity (18) and the degradation of labeled hemoglobin as an indicator of cathepsin D activity (19). Ox-LDL, but not other forms of LDL, induced an extensive reduction in cathepsin B activity (Fig. 6). However, degra- 


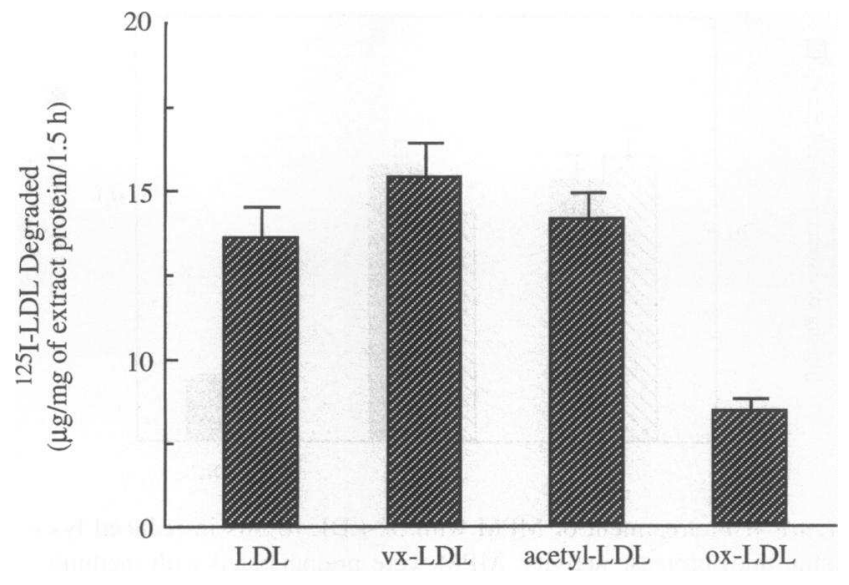

Figure 5. Direct incubation of extracts from untreated MPM with oxLDL reduces lysosomal thiol protease activity. Untreated MPMs were homogenized to obtain whole cell extracts. $5 \mu \mathrm{g}$ of extract protein were first incubated with $5 \mu \mathrm{g}$ protein of LDL, vx-LDL, acetyl-LDL, or oxLDL in a final volume of $50 \mu \mathrm{l}$ of acetate buffer, $\mathrm{pH} 4.0$, for $5 \mathrm{~h}$ followed by the addition of ${ }^{125} \mathrm{I}-\mathrm{LDL}$ ( $50 \mu \mathrm{g}$ protein) in $50 \mu \mathrm{l}$ of acetate buffer with and without DTT for $1.5 \mathrm{~h}$. The amounts of DTT-dependent, TCA-soluble radioactivity were determined as described in Methods.

dation of ${ }^{125}$ I-hemoglobin was unaffected by the presence of any of the LPs tested, suggesting that, unlike cathepsin B, cathepsin $\mathrm{D}$ appears to be resistant to inactivation by ox-LDL. Both soluble and insoluble ox-LDL were able to specifically inhibit cathepsin B in this assay to about the same degree (not shown).

We compared extent of degradation of ${ }^{125} \mathrm{I}-\mathrm{LDL}$ or ${ }^{125} \mathrm{I}-\mathrm{ox}-$ LDL by a mixture of cathepsin B and D over a 24-h period, with cathepsin B activity and CLN hydrolysis measured simultaneously in the same experiment. ${ }^{125} \mathrm{I}-\mathrm{ox}$-LDL showed a reduced degradation by mixture of cathepsin $B$ and $D$ relative to

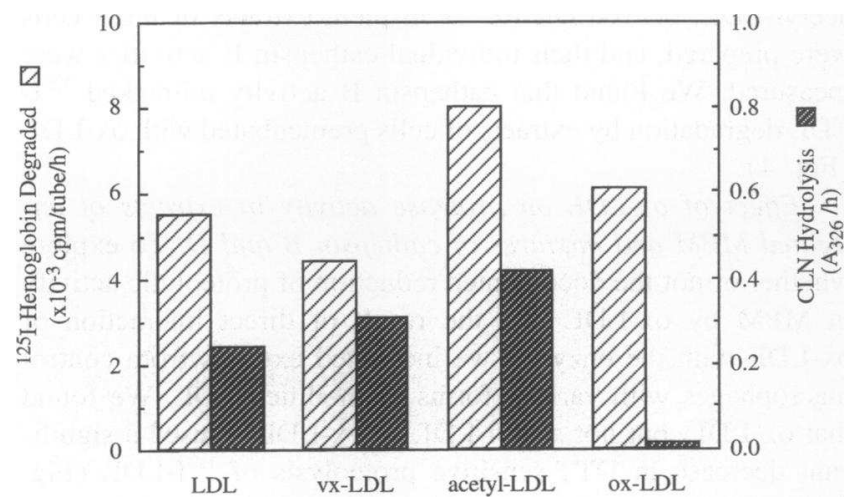

Figure 6. Incubation of cathepsins B and D with ox-LDL reduces cathep$\sin B$ but not cathepsin D activity. A mixture of cathepsin B and D $(0.05 \mathrm{U}$ of each enzyme $/ \mathrm{ml})$ was first incubated with either LDL, vxLDL, acetyl-LDL, or ox-LDL ( $100 \mu \mathrm{g} / \mathrm{ml})$ in acetate buffer, $\mathrm{pH} 4.5$, for $3 \mathrm{~h}$. Then, $25-\mu \mathrm{l}$ aliquots of the above were mixed with $500 \mu \mathrm{l}$ acetate buffer, $\mathrm{pH} 4.5$, containing CLN $\left(2 \times 10^{-4} \mathrm{M}\right)$ or ${ }^{125}$ I-hemoglobin $(208 \mu \mathrm{g} / \mathrm{ml})$. After incubation for $1 \mathrm{~h}, \mathrm{CLN}$ hydrolysis (expressed as absolute absorbance at $326 \mathrm{~nm}$ ) and TCA-soluble label were measured as described in Methods. Data are representative of three separate experiments.
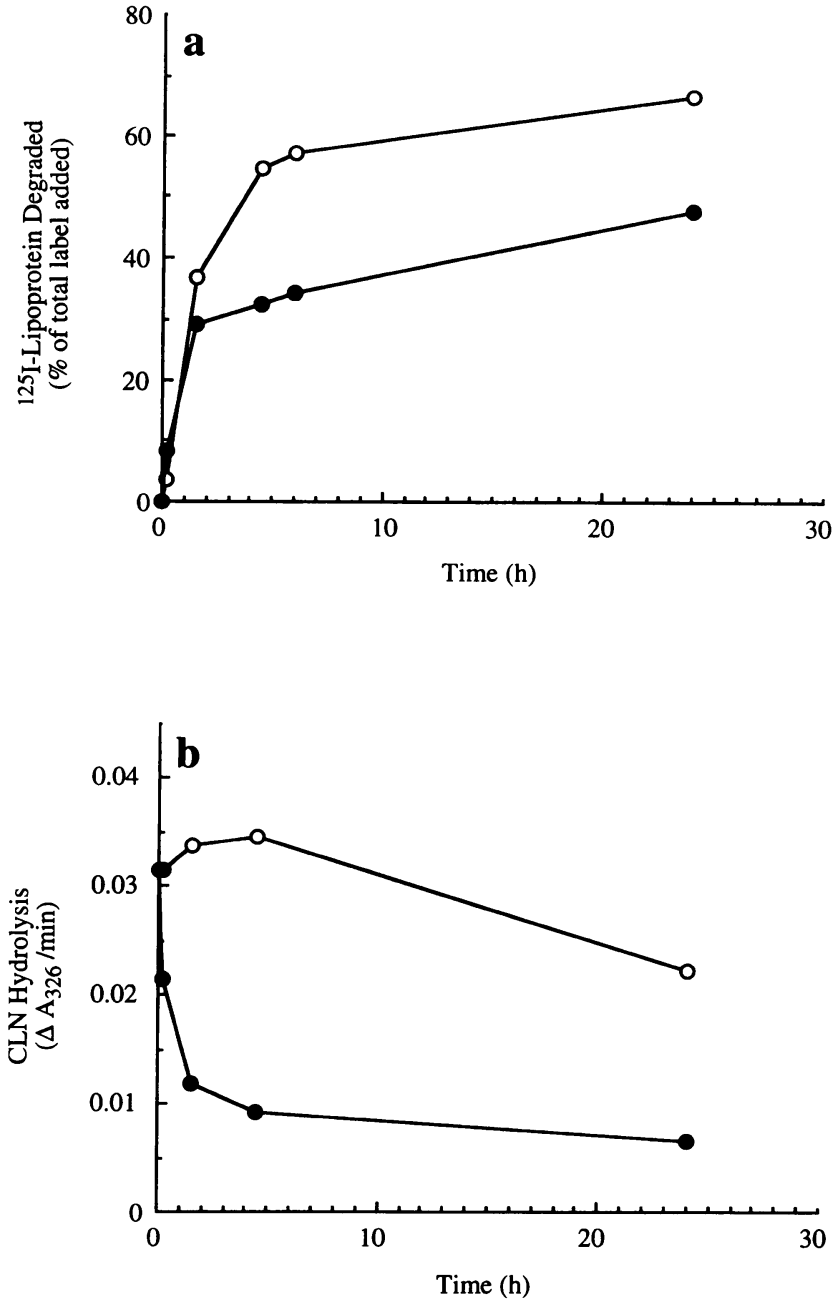

Figure 7. Lower degradation of ox-LDL by a mixture of cathepsin B and $D$ can be attributed, in part, to reduced cathepsin B activity. 200 $\mu \mathrm{l}$ of a mixture of cathepsin B and D $(0.25 \mathrm{U}$ of each enzyme $/ \mathrm{ml})$ was incubated with $15 \mu \mathrm{g}$ of ${ }^{125} \mathrm{I}-\mathrm{LDL}(\mathrm{O})$ or ${ }^{125} \mathrm{I}-\mathrm{ox}-\mathrm{LDL}(\bullet)$ in a final volume of $500 \mu \mathrm{l}$ of acetate buffer, $\mathrm{pH} 4.5$. At the indicated time points, 25- $\mu \mathrm{l}$ aliquots of above mixtures were removed for measurement of TCA-soluble label $(a)$, or $25 \mu \mathrm{l}$ aliquots of above mixtures were mixed with $475 \mu \mathrm{l}$ acetate buffer, $\mathrm{pH} 4.5$, containing $2 \times 10^{-4} \mathrm{M}$ CLN. CLN hydrolysis $(b)$ was measured as described in Methods and expressed as changes in absorbance/min. Data are representative of three separate experiments.

${ }^{125}$ I-LDL (Fig. $7 a$ ), which could also be explained by the greater reduction in cathepsin $B$ activity when the mixture of cathepsin B and D was incubated with ${ }^{125} \mathrm{I}-\mathrm{Ox}$-LDL than when incubated with ${ }^{125}$ I-LDL (Fig. $7 \mathrm{~b}$ ). Similar results were obtained with soluble and insoluble ox-LDL (not shown). The gradual reduction of cathepsin B activity with increasing time in the presence of LDL probably reflects some self-inactivation of cathepsins during the prolonged incubation period.

\section{Discussion}

In this study we have examined whether inactivation of lysosomal proteases by ox-LDL is responsible for the poor degrada- 
tion of ox-LDL in MPM. Pretreatment of cells with ox-LDL was effective in inhibiting the subsequent degradation of not only ox-LDL, but other LPs as well. Since preincubation of cells with vx-LDL or opsonized latex particles did not cause such inhibition, it is unlikely that induction of accumulation of undegraded LP or the process of phagocytosis was responsible for the reduced degradation of other LPs subsequently added. Furthermore, both soluble and insoluble ox-LDL were equally effective in inhibiting the degradation of other LPs in MPM. Inhibition in degradation was not due to compromised LP binding or internalization, since total LP uptake was not appreciably affected by such preincubations. Likewise, it was not due to cytotoxicity, since cells appeared viable, based on morphologic criteria and cell protein levels.

The observation that extracts of cells preincubated with oxLDL demonstrated a reduction in a thiol protease activity represents a key link between this reduced degradation of LPs in cells preincubated with ox-LDL and the reduction in lysosomal thiol protease activity. Since this reduction correlated with a reduction in the hydrolysis of the synthetic substrate CLN, it is probable that the protease most affected is cathepsin B. It was previously shown that LDL is readily degraded to TCA-soluble products by a mixture of cathepsin $B$ and $D(6,9)$. However, in one of these reports neither cathepsin B nor cathepsin D alone could degrade LDL to peptides small enough to be TCAsoluble (6). It was suggested that cathepsin D degrades LDL into larger peptides by cleaving apo B at hydrophobic amino acids, and cathepsin $B$ then degrades these larger peptides into smaller peptides by cleaving at basic residues (6).

We have shown that ox-LDL inhibits thiol proteases in extracts of untreated MPM and cathepsin B in a mixture of cathepsin B and D..This result lends support to the hypothesis that ox-LDL inactivates the enzyme, whereas exposure of enzymes with LDL or vx-LDL causes no inactivation. Since both soluble and insoluble ox-LDL were about equally effective in inhibiting cathepsin B, it is unlikely that physical parameters such as particle aggregation play a role in the underlying mechanism. It still needs to be determined whether LDL oxidized to increasing degrees shows an increasing potency to inactivate cathepsin B.

One potential mechanism for enzyme inactivation is by covalent interaction of components of ox-LDL such as HNE with the enzyme (10-12). HNE was shown to form crosslinks with a number of amino acid side chains (10). Both HNE-lysine adducts (10) and thiol-ether adducts $(11,12)$ have been identified. Recently, thiol-ether adducts between HNE and enzymes with a thiol group at their active site were shown to form, resulting in inactivation of the enzyme $(11,12)$. It is possible that reactive aldehydes present in ox-LDL might form thiolether linkages with the thiol group at the active site of cathepsin $B$, and thereby inactivate the enzyme. Inactivation of cathepsin B by this mechanism would also be consistent with the rapid rate of reduction in enzyme activity following incubation with ox-LDL.

The rationale for performing these studies was to determine whether enzyme inactivation, in addition to substrate modification, plays any role in the deficient degradation of apo B in oxLDL. Since increasing inter- and intramolecular crosslinking of apo B, either in extensively oxidized LDL (21) or in HNEmodified LDL (22), was shown to parallel increasing degrees of poor degradation of LDL (8), it was suggested that substrate modification was responsible for the poor protease degradation of modified apo B (8). However, in our study, when samples of mixtures of cathepsin B and D that had been incubated with ox-LDL were removed during the course of incubation over a 24-h time interval and assessed independently for protease activity, the cathepsin B activity in these samples decreased in parallel with the reduction in ability of the mixture to degrade ${ }^{125} \mathrm{I}-\mathrm{ox}-\mathrm{LDL}$. This result suggests that the reduced degradation of ox-LDL could have been due to inactivation of cathepsin B by the ox-LDL.

In this study we found that the degradation of ${ }^{125} \mathrm{I}$-acetylLDL in MPM appeared to be less affected by preincubation with ox-LDL than the degradation of other LP. Similar results had been reported by other investigators $(6,8)$. Both ligands have been shown to be internalized by the scavenger receptor (2), but others have claimed that ox-LDL is also recognized by a unique receptor $(5,23)$. The different degradation rates could be explained by different intracellular routing of the two ligands.

In summary, we have shown by combinations of studies in cell and cell-free systems that ox-LDL can inhibit the degradation of not only subsequently added ox-LDL but also other LPs as well, and that this inhibition is likely the result of inactivation of cathepsin B activity by the ox-LDL. These results have potentially important pathophysiological repercussions; namely, that if tissue macrophages internalize ox-LDL in atherosclerotic lesions, their capacity to degrade various LP may be impaired. Thus, lipid loading of these cells could occur not only by the accumulation of undegraded ox-LDL, but also by the accumulation of undegraded forms of other LP. Further studies are needed to establish the mechanisms responsible for these events.

\section{Acknowledgments}

The authors wish to thank Dr. Richard Morton for helpful suggestions during the preparation of the manuscript.

This work was supported by NIH Program Project grant HL-29582.

\section{References}

1. Witztum, J. L., and D. Steinberg. 1991. Role of oxidized low density lipoprotein in atherogenesis. J. Clin. Invest. 88:1785-1792.

2. Steinbrecher, U. P., H. Zhang, and M. Lougheed. 1990. Role of oxidatively modified LDL in atherosclerosis. Free Radical. Biol. \& Med. 9:155-168.

3. Ball, R. Y., J. P. Bindman, K. L. H. Carpenter, and M. J. Mitchinson 1986. Oxidized low density lipoprotein induces ceroid accumulation by murine peritoneal macrophages in vitro. Atherosclerosis. 60:173-181.

4. Brown, M. S., and J. L. Goldstein. 1983. Lipoprotein metabolism in the macrophage: implications for cholesterol deposition in atherosclerosis. Annu. Rev. Biochem. 52:223-261.

5. Sparrow, C. P., S. Parthasarathy, and D. Steinberg. 1989. A macrophage receptor that recognizes oxidized low density lipoprotein but not acetylated low density lipoprotein. J. Biol. Chem. 264:2599-2604.

6. Lougheed, M., H. Zhang, and U. P. Steinbrecher. 1991. Oxidized low density lipoprotein is resistant to cathepsins and accumulates within macrophages. J. Biol. Chem. 266:14519-14525.

7. Roma, P., F. Bornini, R. Fogliatto, S. M. Bertulli, S. Negri, R. Fumagalli, and A. Catapano. 1992. Defective catabolism of oxidized LDL by $\mathrm{J774}$ murine macrophages. J. Lipid Res. 33:819-829.

8. Jessup, W., E. L. Mander, and R. T. Dean. 1992. The intracellular storage and turnover of apolipoprotein B of oxidized LDL in macrophages. Biochim. Biophys. Acta. 1126:167-177.

9. Hoff, H. F., N. Zyromski, D. Armstrong, and J. O'Neil. 1993. Aggregation as well as chemical modification of LDL during oxidation is responsible for poor processing in macrophages. J. Lipid Res. 34:1919-1929.

10. Esterbauer, H., R. G. Schaur, and H. Zollner. 1991. Chemistry and biochemistry of 4-hydroxynonenal, malonaldehyde and related aldehydes. Free Radical Biol. \& Med. 11:81-128. 
11. Uchida, K., and E. R. Stadtman. 1992. Selective cleavage of thioether linkage in proteins modified with 4-hydroxynonenal. Proc. Natl. Acad. Sci. USA. 89:5611-5615.

12. Uchida, K., and E. R. Stadtman. 1993. Covalent attachment of 4-hydroxynonenal to glyceraldehyde-3-phosphate dehydrogenase. A possible involvement of intra- and intermolecular cross-linking reaction. J. Biol. Chem. 268:63886393.

13. Hatch, F. T., and R. S. Lees. 1968. Practical method for plasma lipoprotein analysis. Adv. Lipid Res. 6:2-63.

14. McFarlane, A. S. 1958. Efficient trace-labeling of proteins with iodine. Nature (Lond.). 182:53-57.

15. Bilheimer, D. W., S. Eisenberg, and R. I. Levy. 1972. The metabolism of very low density lipoprotein proteins. I. Preliminary in vitro and in vivo observations. Biochim. Biophys. Acta. 260:212-221.

16. Goldstein, J. L., Y. K. Ho, S. K. Basu, and M. S. Brown. 1979. Binding site on macrophages that mediates uptake and degradation of acetylated low density lipoprotein, producing massive cholesterol deposition. Proc. Natl. Acad. Sci. USA. 76:333-337.

17. Khoo, J. C., E. Miller, P. McLaughlin, and D. Steinberg. 1988. Enhanced macrophage uptake of low density lipoprotein after self-aggregation. Arteriosclerosis. 8:348-358.

18. Bajkowski, A. S., and A. Frankfater. 1975. Specific spectrophotometric assays for cathepsin $\mathrm{B}_{1}$. Anal. Biochem. 68:119-127.

19. Takahashi, T., and J. Tang. 1981. Cathepsin D from porcine and bovine spleen. Methods Enzymol. 80:565-581.

20. Smith, P. K., R. I. Krohn, G. T. Hermanson, A. K. Mallia, F. H. Gartner, M. D. Provenzano, E. K. Fujimoto, N. M. Goeke, B. J. Olson, and D. C. Klenk. 1985. Measurement of protein using bicinchoninic acid. Anal. Biochem. 150:7685.

21. Hoff, H. F., T. E. Whitaker, and J. O'Neil. 1992. Oxidation of LDL leads to particle aggregation and altered macrophage recognition. J. Biol. Chem. 267:602-609.

22. Hoff, H. F., J. O'Neil, G. M. Chisolm, T. B. Cole, O. Quehenberger, H Esterbauer, and G. Jürgens. 1989. Modification of LDL with 4-hydroxynonenal induces uptake of LDL by macrophages. Arteriosclerosis. 9:538-549.

23. Arai, H., T. Kita, M. Yokode, S. Narumiya, and C. Kawai. 1989. Multiple receptors for modified low density lipoproteins in mouse peritoneal macrophages: different uptake mechanisms for acetylated and oxidized low density lipoproteins. Biochem. Biophys. Res. Commun. 159:1375-1382. 